\title{
Paper by M. Ivković, W. J. Gapare, A. Albarquez, J. Ilic, M. B. Powell and H. X. Wu "Prediction of wood stiffness, strength and shrinkage in juvenile wood of radiata pine", in Wood Science and Technology 43(3-4); 237-257 (2009)
}

\section{R. D. Burdon}

Published online: 11 October 2009

(C) Springer-Verlag 2009

Regarding the above paper, I see it as an excellent, solid research contribution, but I must take issue on some points.

The points centre on the concept of juvenile wood, and a citation of my own work on the topic (Burdon et al. 2004). In my paper, it is argued that a pith-to-bark progression in wood properties should be termed a corewood-outerwood progression, and that the concept of a juvenile to mature wood progression should properly be reserved for a progression up from the base of the stem. Since that paper is based on the rejection of widely used terminology for juvenile and mature wood, it had an obvious potential to be contentious. Even so, I consider that if authors cite the paper, they need to make clear whether or not they accept the central thesis.

As it is, Ivkovic et al. have stayed with the old concept of juvenile wood representing the first few rings from the pith (Introduction, paragraph 2, first sentence), but then immediately cite my work as if it concurred with the old concept, which of course my work did not.

Following that there are inconsistencies in the use of terminology, and thus in conceptual treatment. In the penultimate line of the next paragraph, reference is made, essentially without lead-in, to "the corewood zone (near the pith)". Furthermore, on page 245, 4th last line, reference comes, again without lead-in, to "juvenile corewood", which I see as being actually correct for the material in question. Finally, in the penultimate paragraph of the text, reference is made in line 1 to "juvenile wood" but later on to "juvenile corewood".

I realise that the authors may have a problem through having been funded under a programme that was designated the Juvenile Wood Initiative, although it is really addressing corewood. However, I do not believe that this consideration should be allowed to compromise the science.

R. D. Burdon (四)

Scion (New Zealand Forest Research Institute Ltd), Private Bag 3020, Rotorua 3046, New Zealand e-mail: Rowland.burdon@scionresearch.com 


\section{Reference}

Burdon RD, Kibblewhite RP, Walker JCF, Megraw RA, Evans R, Cown DJ (2004) Juvenile versus mature wood: a new concept, orthogonal to corewood versus outerwood, with special reference to Pinus radiata and P. taeda. For Sci 50(4):399-415 